\title{
Thinking through enactive agency: sense-making, bio-semiosis and the ontologies of organismic worlds
}

\author{
Paulo De Jesus ${ }^{1}$ (D) \\ Published online: 2 March 2018 \\ (C) The Author(s) 2018. This article is an open access publication
}

\begin{abstract}
According to enactivism all living systems, from single cell organisms to human beings, are ontologically endowed with some form of teleological and sensemaking agency. Furthermore, enactivists maintain that: (i) there is no fixed pregiven world and as a consequence (ii) all organisms "bring forth" their own unique "worlds" through processes of sense-making. The first half of the paper takes these two ontological claims as its central focus and aims to clarify and make explicit the arguments and motivations underlying them. Our analysis here highlights three distinct but connected problems for enactivism: (i) these arguments do not and cannot guarantee that there is no pregiven world, instead, they (ii) end up generating a contradiction whereby a pregiven world seems to in fact be tacitly presupposed by virtue of (iii) a reliance on a tacit epistemic perspectivalism which is also inherently representationalist and as a consequence makes it difficult to satisfactorily account for the ontological plurality of worlds. Taking these considerations on board, the second half of the paper then aims to develop a more robust ontologically grounded enactivism. Drawing from biosemiotic enactivism, science and technology studies and anthropology, the paper aims to present an account which both rejects a pregiven world and coherently accounts for how organisms bring forth ontologically multiple worlds.
\end{abstract}

Keywords Agency B Biosemiotic enactivism - Enactive cognitive science · Epistemic perspectivalism $\cdot$ Ontology $\cdot$ Organismic worlds $\cdot$ Representationalism

\section{Introduction}

Traditional conceptions of agency both within cognitive science (Pylyshyn 1988) and analytic philosophy (Davidson 1963; Fodor 1975) have tended to take a distinctively

Paulo De Jesus

paulo242@hotmail.com

1 Department of Computing, Goldsmiths, University of London, London, England 
anthropocentric stance on questions surrounding agents and agency. Human adults serve as the incontestable prototypical example of an agent, while only a subset of its doings, doings constituted by reason, intention and deliberate planning, are regarded as true action. In this picture only creatures which possess specific types of internal mental states such as beliefs and desires can be considered genuine agents.

Recent approaches within cognitive science and philosophy of mind, so-called 4E approaches, have however begun challenging various aspects of mainstream accounts of action. One such approach, enactivism (Colombetti 2014; Di Paolo 2009; Stewart et al. 2010; Thompson 2007) ${ }^{1}$ has over the last decade developed an account of agency which it argues can serve as the foundation for a non-cognitivist, nonrepresentationalist embodied cognitive science. It is an account grounded on fundamental biological principles and as such concerns itself not only with human agency but emphasises a strong agential continuity between all living systems (De Jesus 2016a; Di Paolo 2005; Froese and Ziemke 2009; Thompson 2007).

This conception of agency, which enactivism recasts in terms of "sense-making", has two mutually supporting ontological components: on the one hand sense-making is argued to be an intrinsic characteristic of all living systems. On the other hand, by virtue of being sense-making agents, organisms are argued to also "bring forth" their own unique "worlds". The main aim of this paper is to first present the various arguments and motivations for these two ontological components of agency and then to interrogate them. After showing that enactivism tends to epistemologize ontology when arguing for the ubiquitous nature of sense-making, we then turn our focus to assessing the claims that there is no pregiven world only a multiplicity of brought forth worlds. Here we find that the central argument deployed to support both these claims a history of structural coupling - is not only incapable of delivering what it intends but more problematically appears to have some counterintuitive and counterproductive consequences. It is then argued that the primary reason for this is that the enactive account is essentially grounded on an epistemic perspectivalism. The first half of the paper concludes by arguing that this epistemic perspectivalism ultimately makes it difficult, if nor impossible, for enactivism to adequately account for the rich ontologies of brought forth worlds.

The second half of the paper is then dedicated to sketching out an alternative route towards ontological multiplicity. The paper aims to present an account which can plausibly overcome the conviction that there is a pregiven world whilst also being able to explain how organisms do ontologically bring forth multiple worlds without reducing these worlds to mere epistemic perspectives. In order to do so it draws from "biosemiotic enactivism" (De Jesus 2016b), science and technology studies and “ontological anthropology" (Kohn 2013; Latour 2013; Law 2004; Mol 2002). With the aid of this work it is suggested that, if we want to take the bio-semiotic (sensemaking) worlds of nonhuman organisms seriously, we need to go beyond a narrow

\footnotetext{
${ }^{1}$ The label "enactivism" has been applied to a number of subtly different but theoretically overlapping noncognitivist approaches to cognition. Hutto and Myin (2013) distinguish two different branches of enactivism: "autopoietic enactivism" and "sensorimotor enactivism". To this we can add Hutto and Myin's own "radical enactivism" and the "biosemiotic enactivism" recently proposed by De Jesus (2016b). Throughout the paper, unless otherwise specified, whenever referring to enactivism I have in mind autopoietic enactivism. I refrain from using the term autopoietic enactivism here on the grounds that, as an enactive approach, it is the only one to have thus far developed an account of agency.
} 
epistemological concern for how it is that humans, at some particular time or in some particular place, go about making sense of them. In order to do so it is suggested that we need to first and foremost shift focus from epistemology to ontology: from thinking about towards being with and the concrete being of living organisms.

The paper starts by introducing the enactive account of agency. The following three sections are then dedicated to teasing out some of the epistemic and ontological roots of the account. Section two presents the arguments for the ontological conception of agency while section three explores what it means to bring forth a world rather than find it pregiven. These sections moreover also aim to clarify in what sense the enactive account of agency should be understood as an ontological rather than simply an epistemological account. Section four concludes the first half of the paper by showing how the various arguments deployed to argue for these claims lead enactivism not only into an internal contradiction but also renders it unable to adequately account for the ontological multiplicity of organismic worlds. The second half of the paper then presents a biosemiotic enactivist inspired account which aims to avoid the highlighted difficulties and attempts to coherently account for the ontological multiplicity of organismic worlds.

\section{The enactive account of agency}

John Searle (1980) observes that "Cognitive Science is likely to make little progress in the study of human behaviour until we have a clear account of what human action is". The enactive account of agency can be understood as an attempt to provide cognitive science with precisely such a clear account of action. However, it goes even further by providing an account which is not only naturalistic and non-reductive but also not restricted to human beings. This section will briefly introduce this account of agency.

In a landmark paper detailing the enactive account of agency Barandiaran, Di Paolo, and Rohde (2009) identify three central characteristics which (i) any theory of agency must account for and (ii) form the necessary and sufficient conditions for agency, These key characteristics are, individuality, interactional asymmetry, and normativity. Let us examine these conditions in turn.

\subsection{Individuality}

A naturalist theory of agency must be able to account for how a system can be identifiable as a separate entity from its environment. Barandiaran et al. (ibid. p. 4) note that, "in order for a system to be an agent, there must be a distinction between the system and its environment". The notion of individuation used here is crucial for the enactive framework and is at the core of not only agency but its account of life and mind more generally. However, it is not just individuation which interests enactivism but self-individuation. According to enactivism living systems are a special sub-class of self-organising, self-creating, dynamic systems, which are autonomous, or operationally closed and capable of creating their own boundaries (Di Paolo 2005, 2009; De Jaegher and Froese 2009; Thompson 2007). Such systems, by virtue of being selforganising and self-constituting, also have the capacity to define themselves as distinct individuals. This self-individuating identity is argued to be grounded on a "dynamic 
network of precarious processes where each process is enabled by other processes in the network and also contributes to enable other processes in the network" (Kyselo and Di Paolo 2015). According to Barandiaran et al. (ibid.), this dynamic organisation enables the system to distinguish itself from its environment and is therefore not a distinction which is or needs to be made by an external observer.

To illustrate the criterion of individuality it will be worth considering the difference between living organisms and mechanical devices. Within a mechanical system, Barandiaran et al. note, "no intrinsic force or process is lumping the components together, nor has the system as a whole (independently of us) a specific way of functioning and demarcating itself from the rest" (ibid. p. 3). This means that both the boundaries and functionality of mechanical devices are externally defined by an observer. By contrast living organisms are self-constructed from the inside and do not need an external observer to endow them with individuality or functionality. Living organisms are therefore self-individuating and capable of defining their systemic identities from the inside out such that in the process they both define themselves and their environment.

Before moving on it is important to highlight the purported ontological nature of this criterion. As Stapleton and Froese (2015, p. 221) argue, "[o]ntological individuation in this respect refers to more than an appropriate posit relative to an explanatory project; it is a strong claim about the fundamental status of minimal living systems. On this view, ontological individuation is necessarily based on self-individuation, of which autopoiesis is one fundamental example". In other words, self-individuation is an ontological feature of all living systems.

\subsection{Interactive asymmetry}

Once we have a self-individuating entity we can begin to understand it rather than its environment as the source of its own actions (McGann 2015). The key notion of interactional asymmetry thus concerns the responsibility an agent has for its own action. A theory of agency must account for why responsibility for an action is allocated to the agent rather than the environment, it must explain what constitutes asymmetric relations between the agent and its environment. As Barandiaran et al. point out, agents exchange matter and energy with their environment and are therefore coupled to it, but "the concept of agency is intuitively associated with that of action, not mere system-environment coupling or exchange" (ibid. p. 3).

Agents are thus responsible for what they $d o$, they require the ability to affect and alter the parameters of their coupling with the environment, changes in the state of the agent enables changes of the parameters of its coupling. Agent and environment thus play different roles in this coupling. However, as Barandiaran et al. maintain, this should not be taken to mean that agency is something which occurs solely within the agent but rather something which emerges in the interaction between agent and environment.

\subsection{Normativity}

The final key characteristic of agency is normativity, which requires that actions are purposive in nature. Agency is not a mere movement or simple modulation but involves 
regulation. From the enactive perspective biological normativity is co-emergent with individuality and guides interactive asymmetry such that the system is capable of teleologically ${ }^{2}$ regulating itself rather then be passively modulated from the outside. But what exactly is meant by teleological here and how does it connect to biological normativity? According to Barandiaran et al. actions are necessarily purposive. An agent acts and thus regulates itself in order to achieve something, there is something it is trying to do and in so doing the very attempt can either succeed or fail. This success or failure of action is relative to the agent itself, not an outside observer, and thus both teleological and normative. Enactivism regards this as an essential component of all living systems which any adequate theory of agency must account for. Actions therefore, unlike random movements, are teleological, goal-directed and hence normative. However, actions are also teleological in a second sense, they are related to meaning and value-guided behaviour (Barrett 2015; De Jesus 2016a; Di Paolo 2005; Weber and Varela 2002).

According to Di Paolo (2005), because life itself is an inherently fragile affair, living systems qua autonomous systems must continuously maintain themselves under "precarious conditions". As these systems are under constant threat from the environment they need to actively work in order to affirm their existence. Enactivists introduce the notion of adaptivity at this point to foreground not only how systems regulate and monitor themselves in relation to viable or unviable conditions but also how these regulations lead to the emergence of various degrees of concern (Colombetti 2014; Di Paolo 2005; Thompson 2007). Enactivists maintain that because adaptivity allows systems to selfmonitor and self-regulate themselves in relation to their own intrinsically generated viability condition, various degrees of concern, subjectivity and value guided behaviour emerge for the system itself. It is with the emergence of a "minimal concern" for selfpreservation and self-interest that adaptively autonomous systems at the same time develop a unique teleological point of view on the world from which environmental properties and interactions are evaluated, pursued and acquire meaning and value.

The paradigmatic example of a $E$. coli bacterium is regularly introduced to illustrate these two distinct senses of teleology involved in agential behaviour. In order to maintain itself an E. coli bacterium swims towards higher concentrations of sucrose and away from noxious substances. This is achieved by virtue of the capacity the bacterium has for regulating its own constitutive network of processes with respect to its viability conditions. Conditions are registered as unviable when the system encounters noxious substances and as viable when it encounters higher concentrations of sucrose. For enactivism this is an adaptive teleological process whereby the bacterium (i) acts in order to maintain itself in accordance to its own self-generated viability conditions and at the same time also (ii) evaluates its surroundings such that certain properties within this surrounding environment acquire meaning and are valuable for the bacterium itself. Thus noxious substances become something which need to be

\footnotetext{
${ }^{2}$ Although the notion of teleology as developed within enactivism is done so in contradistinction to notions of teleonomy found within the philosophy of science and biology (see Mayr 1992), it has not directly engaged with this work in any way. As a reviewer correctly pointed out it would be both informative and beneficial for the development of enactivism if it were to engage with this broader literature. As this particular endeavour would take us to far afield in this paper, I can only point this out here and gesture towards both this unexplored territory and avenues for future work. My gratitude to a reviewer for bringing this important point to my attention.
} 
avoided while more sugar is something to be sought. Enactivists call this process of environmental evaluation by an adaptively autonomous system sense-making. For enactivism genuine agency is therefore an intrinsic and thus ontological feature of all systems capable of partaking in processes of sense-making.

To sum up, the enactive proposal argues that agency requires a self-individuating autonomous entity which can partake in asymmetric, purposeful interaction, with its environment. A self-individuating entity is one which has the capacity to create itself as an integrated individual distinct from but able to adapt to changes in the environment. Although under continuous threat from its environment, an agent is not completely at its mercy, but manipulates it in order to satisfy internally generated needs and goals. It is by virtue of having to keep itself in existence, by acting, that both goal-directed and normative, meaningful, valued-laden behaviour, emerges. This distinctive type of agency is what enactivists mean by sense-making. ${ }^{3}$

In the following sections I want to critically engage this account of agency by further honing our focus on the notion of sense-making. Our first move towards this end will be to introduce some of the motivations and arguments supporting the ontology of sense-making.

\section{Clarifying the epistemic and ontological foundations of enactive agency}

This section takes a closer look at the enactive account of agency by focusing explicitly on sense-making as a distinctive type of agency. I present some of the arguments made for this type of agency, clarify their ontological and epistemic status and conclude by highlighting some problems.

\subsection{The case for the ontology of enactive agency}

Broadly speaking ontology is concerned with what there is while epistemology is concerned with what we know, or think we know, about what there is. As we saw in the previous section the enactive account of agency was explicitly presented in ontological terms. In particular we saw two distinct, though related, ontological claims being made: that all living systems are (i) self-individuating and (ii) sense-making agents. Of particular interest for this paper is claim (ii). Recall the example of a single cell bacterium swimming up a sucrose gradient. Enactivists regard such a bacterium as providing the most minimal instance of intrinsic ontological agency - sense-making - in nature. ${ }^{4}$ Sense-making is therefore an intrinsic property of living systems and not merely an epistemic posit.

Not everyone has been convinced by these claims. Some theorists have pointed out that self-individuation does not appear sufficient for agency in this sense (Villalobos and Ward 2015). The general skepticism here can be traced back to Kant, who saw nonhuman organisms as active self-organising/self-sustaining systems but nonetheless

\footnotetext{
$\overline{3}$ In what follows I will treat sense-making as coextensive with agency and will use them interchangeably. I do this on the grounds that for enactivism all agents qua agents necessarily act and all action qua actions are processes of sense-making. Therefore to act is to partake in processes of sense-making.

${ }^{4}$ But see Meacham (2016) who challenges the strongly held conviction that cognition cannot occur below the cellular level.
} 
regarded teleology as an epistemic ascription. According to Kant there is no intrinsic ontological purposes in the domain of nonhuman organisms and as such the very notion of intrinsic teleology is nothing more than a useful heuristic projected onto organisms from the outside. The ontological properties which enactivists claim are part and parcel of agency are on this reading simply epistemic posits.

Indeed, the theory of autopoiesis proposed by Maturana and Varela (1980) which is itself an important historical precursor to enactivism, reaches similar Kantian conclusions. This work is instructive in the current context because in its original formulation autopoietic systems were regarded as purposeless machines (see Maturana 1975). As with current enactivism, autopoietic theory also makes very strong ontological claims about the essential nature of living systems, but which are however diametrically opposed to those made by enactivists. Villalobos and Ward (2015) summarise the distinction between autopoietic theory and enactivism rather starkly as follows: "both theories [...] subscribe to the view that living beings exhibit organizational closure. Nonetheless, starting from this point in common, these theories seem to arrive at very different conclusions about living beings. In the enactive case, we have the view of a system that, being autonomous, emerges as a self that is intentionally directed at a world, that defines an inside and an outside, and to which the environment appears endowed with significance and value. In the other case, we have the view of a system that does not distinguish itself from anything, to which there is no inside and outside, and to which something like 'the environment' or 'the world' does not exist at all". Traditional autopoietic theory and current enactivism thus differ only in the conclusions they each draw from the same epistemic observations: the latter but not the former sees in autopoiesis a minimal form of intrinsic goal-direct sensemaking. A suitably modified account of autopoiesis (Di Paolo 2005) can indeed guarantee intrinsic (ontological) teleological sense-making agency.

Given these two diametrically opposing positions, enactivists could perhaps follow Fred Cummins's (2014) suggestion that one could take a middle ground between these two extremes. One which, according to Cummins, could perfectly accommodate both intuitions. According to Cummins enactivism should embrace its constructivist roots and acknowledge the role of the observer in the attribution of agency. It is only by bringing back the observer into the picture that, Cummins maintains, the notion of agency can truly make sense. Indeed, Cummins (ibid. p. 107) goes on to argue that, with regards to the purported difference between Maturana and enactivism, "there does not seem to be a fundamental disagreement here, but rather an occasional failure to knowingly distinguish between the domain of description, as things appear to an observer who is, herself, an agent, and the domain of operation of the system". It is on this basis that Cummins urges enactivists to be careful not to conflate autonomy (understood in terms of generative mechanisms) with agency (regarded to be a observer relative property). Although arguably presenting an elegant solution to the antinomy, this deflationary position is however unlikely to appease all enactivists as it regards sensemaking in epistemic rather than ontological terms.

But exactly how do enactivists go about making their case for its ontological conclusions? Within the enactive literature one can broadly identify two types of arguments routinely used as support for its ontological conception of sense- 
making: (i) the mechanistic argument and (ii) the phenomenological argument. Mechanistic arguments postulate the existence of generative mechanisms which are argued to underlie or give rise to teleological behaviour (Barandiaran et al. 2009; Cummins 2014). While the phenomenological argument takes lived experiences as an indicator of intrinsic teleology across the phylogenetic scale (Di Paolo 2005; Thompson 2007; Weber and Varela 2002).

A good example of the mechanistic argument is found in the work of Egbert and colleagues (2010) who attempt to model bacterial chemotaxis on the basis of the three criteria introduced above. Here the mechanisms of metabolism are modelled as far from thermodynamic equilibrium cycles of autocatalytic reactions, which is argued to capture some aspects of precarious operational closure, while the bacterium's behavioural regulations with its environment are modulated by metabolism and modelled accordingly. The intricate details of these models need not concern us here, what is important for our purpose is to highlight the fact that these models are used as a means to give the ontological conclusion plausibility. The authors attempt to show that there is a deep link between metabolism (processes of self-construction) and behaviour (processes of environmental regulations) as the enactive account proposes. The model is thus argued to not only empirically capture important behavioural properties of the bacterium but also provides justification for enactivism's ontological claims of intrinsic teleology (Di Paolo and Thompson 2014). Mechanistic arguments thus draw on empirical research and modelling to give credence to and support for sense-making.

As with the mechanistic argument the phenomenological argument equally functions as a means to support enactivism's strong ontological conception of sense-making. However, the phenomenological argument does not rely on empirical models but on human phenomenological considerations, to argue its case. According to this line of argument, we are justified in regarding nonhuman organisms as ontologically agentive on the grounds that, as Jonas (1966) argued, "life can only be known by life". The general idea here is that because we are ourselves beings who strive to maintain our existence we are therefore capable of recognising this striving in others. As Di Paolo (2005) points out, if we were disembodied intellects, we would have no means of understanding this fact and the notion of agency would have no grounding. Therefore, according to Thompson (2004, p. 90), "[t]o make the link from matter to life and mind, from physics to biology, one needs concepts like organism and autopoiesis, but such concepts are available only to an embodied mind with firsthand experience of its own living body". This strongly suggests that the phenomenological argument subsumes and has priority over the mechanistic one (cf. De Jesus 2016a).

The point is similarly argued for by Di Paolo et al. (2010, pp. 44-45) who maintain that "the inward aspect of life cannot be demonstrated using our current scientific tools. This does not make it any less factual for Jonas. He knows that all life is connected along an evolutionary continuum, and he knows that we ourselves are embodied living creatures with an inner life. This is how we can then know that living beings are forms of existence and that they also have an inner life". It is thus on the basis of these phenomenological considerations that we can justify that teleology and sense-making are ontologically intrinsic to all living organisms. 
It is not the aim of this paper to directly assess the validity or otherwise of the arguments made in this section. ${ }^{5}$ Rather, the important issue for our purpose here is to highlight how these arguments reach ontological conclusions from strictly epistemic considerations. Both enactive arguments, as well as the debate between autopoietic theory and enactivism, move from epistemic premises about what is known, either through subjective experience or by modelling, to ontological conclusions about what there $i s$, namely systems endowed with or lacking certain properties. What we have here then is an example of a broader pervasive trend within enactivism, which we will be returning to and clarifying throughout the rest of the paper, to uncritically epistemologize ontology ( $\mathrm{Gad}$ et al. 2015). The "ontological domain" of concern for enactivists is ultimately accessed and them mobilised via a theorist's constructed knowledge of the world, either through phenomenological experience or models, concepts and abstract ideas, rather than via a direct engagement with the materiality of the world. We will be returning to this issue below, for now we simply need to bear in mind that enactivism conflates questions of how we know with questions about what there is and as a consequence systematically dissolves the ontological into the epistemic.

This section has explored some of the motivations and arguments for enactivism's distinctive ontological conception of agency. We ended by highlighting the obfuscated epistemic nature of these arguments. However, a further crucial aspect of enactivism's rich account of agency is that, through processes of sense-making, organisms are said to bring forth worlds. It is the arguments and motivations for this radical sounding claim that we now need to appraise.

\subsection{Sense-making: Worlds are brought forth not pregiven}

According to enactivism there is no fixed pregiven world and as a consequence, through processes of sense-making, all organisms are argued to "bring forth" their own unique "worlds". Although both these claims are persistently invoked in the enactive literature it is by and large done so uncritically. In this section I aim to remedy this by digging a little deeper into these claims and render explicit the central argument made for them. This will then enable us, in the following section, to try and establish whether this argument entails what enactivists claim it does.

To appreciate the motivations for the proposal that living organisms bring forth worlds we need to go back to the original conception of enaction. As Vörös et al. (2016) correctly observe, enactivism as originally introduced by Varela et al. (1991), had as its main goal the ambition "to find a way to crack the old chestnut of realism and idealism". According to Varela et al., this requires that we overcome two deeply intrenched and mutually supporting ideas: (i) that we have internal mental representations mediating our access to a (ii) pregiven, perceiver-independent, world. As the authors point out, for realists mental representations are used to bridge that which is outside to what is inside, while for idealists mental representations are used to project

\footnotetext{
${ }^{5}$ It is however worth noting that the fact that one can effectively model a certain class of properties does not by itself imply that the system being so modelled ontologically possesses these properties. Nor moreover are my own experiences sufficient to guarantee that other living organisms do or must have ontologically similar experiences (see De Jesus 2016a, 2016c).
} 
what is inner. Both realism and idealism moreover cannot get off the ground without assuming that there is a fixed pregiven world. That is, a world which is "out there" with pregiven intrinsic properties and structures which are independent of organisms. But, Varela et al. argue, if there is no pregiven world then there is no need to internally represent it. It is by rejecting both these ideas that we can "move away from the idea of the world as independent and extrinsic to the idea of a world as inseparable from the structure of $[\ldots]$ processes of self-modification" (ibid, p. 139).

It is noteworthy that Varela et al. dedicate a considerable amount of time and attention to rejecting the assumption that there is a pregiven perceiver-independent world, but spend considerably less time and attention on explaining or clarifying the exact ontological status of perceiver-dependent "worlds". Indeed this continues to be an oversight of the enactive account more broadly. But if one rejects the existence of a pregiven perceiver-independent world, then the question as to what there is, becomes rather pressing (cf. Werner 2017). Nonetheless, although this question is never directly addressed, it is however indirectly answered by the claim that the organism "brings forth" its own world. According to Varela et al., "cognition in its most encompassing sense consists in the enactment or a bringing forth of a world by a viable history of structural coupling" (Varela et al. 1991, p. 205 italics added). While suggesting that the world is brought forth does not in and of itself explain what there is, the notion of structural coupling does however point us towards what exactly enactivism is committed to, which in turn will shed some light on how best to address the ontological question.

Indeed the importance of structural coupling becomes obviously apparent once we enquire into exactly how the world is perceiver-dependent. Once we establish that structural coupling is that by virtue of which organisms are capable of bringing forth a world, we will at the same time not only be able to clarify (i) in what way organisms bring forth a world but also (ii) the ontological status of these worlds. This will in turn enable us to render explicit a further example of enactivism's epistemologizing of ontology. But first we need to turn to the influential work of Maturana and Varela to help illustrate these various points.

According to Maturana and Varela (1980) there is a co-evolution within the processes of structural coupling which entail the collapse of the traditional epistemic dichotomy of objectivity and subjectivity. Thus subject and object, the knower and the known, are in continuously reciprocal and simultaneous specifications which codefine each other. It is active coupling of both the structural properties of living organisms and the structural properties of their respective environments which enables the perception of the world and with it the ability to make sense of this world. Consequently, it is my structure which allows for a world to be brought forth. As Proulx (2008, pp. 21-22) clarifies "I bring forth the physical world's attributes when I give/create meaning to it - I acknowledge their physical "presence" by bringing them forth. If I do not bring them forth, the physical world's attributes will still be "there," but they will remain unnoticed, not made sense of and kept "in the dark". It is in this sense that the physical attributes themselves are brought forth by my interaction with them (if I perceive them). In some sense, I make the physical world emerge".

Note however that, according to enactivism, structural coupling is essentially a symmetrical notion which does not involve the genuine interactive asymmetry of agentive sense-making (see Di Paolo 2009). As we have seen sense-making, unlike 
mere structural coupling, requires that the system regulates its environmental coupling and thus take "responsibility" for its actions. Nonetheless, the important point to note is that either way, it is the organism's morphological/structural make-up - its embodiment and perceptual apparatus - which ultimately determines those features of the world to which it is sensitive (Zahidi 2014). Insofar as this is the case, worlds can therefore be said to be brought forth, by virtue of the organism's distinctively embodied perceptual system. Moreover, it is through distinct structural couplings that different organisms also acquire different perspectives on that world.

This is perhaps best illustrated by Varela et al. (1991) central example, that of colour perception, for the enactment of a world. According to the authors, colour perception can be regarded as a "paradigm of a cognitive domain that is neither pregiven nor represented but rather experiential and enacted" (ibid, p. 171). Varela et al. argue that colour is not a property "out there" in the world but something which, through a history of structural coupling, different organisms experience in their own unique ways. Thus, "different histories of structural coupling for birds, fishes, insects, and primates have enacted or brought forth different perceived worlds of color" (ibid, p. 183). Because, according to Varela et al., experience of colour does not directly correspond one-to-one with any properties in the world, colours are not pregiven worldly properties but uniquely brought forth by different organisms with different morphological structures: "cognition depends upon the kinds of experience that come from having a body with various sensorimotor capacities" (ibid, p. 172, italics added).

We can further clarify this constitutive role of embodiment and structural coupling in the bringing forth of worlds with the example of the single cell bacterium. Recall that it was its sensorimotor coupling with the environment, understood as adaptive autonomy, that grounded the co-emergence of meaning and allowed it to "transform" sucrose into a valuable nutrient. It is by virtue of both its morphological/structural properties and the part of the physical world it inhabits, that certain states and properties of the world become salient for it. But note that, due to the asymmetrical nature of this process, embodiment is that which ultimately determines what becomes meaningful for the organism. That which grounds the bacterium's "perspective", "point of view" and ultimately its "world". So it is that the bacterium's world is brought forth by its sensorimotor activity (Di Paolo 2009; Thompson 2007; Weber and Varela 2002). From this standard example enactivists can then generalise to other organisms by arguing that their different morphological structures, different embodiments, give rise to different perceiver-dependent worlds.

Echoing Varela et al., Chemero (1998) helps put a finer point on this view by noting that "if humans and ticks and rats and so on are all able to live very successfully in the very different worlds constituted by their perceptual systems, there can be no principled reason to privilege the human world (or any other world) as the world-in-itself. [...] Thus the ontology implied by the usual human categories has no claim on being the world-in-itself". Again, what this quote succinctly highlights, is that according to enactivism the world is perceiver-dependent by virtue of the different perceptual systems different organisms possess. It is because bacteria, tics and rats have perceptual systems with different characteristics that the worlds they bring forth vary dramatically from the world a human being experiences. This in a nutshell is a guiding thread of the enactive account of sense-making and the central argument which serves as the template for the broader notion of brought forth worlds. 
This should now significantly help clarify both why enactivists believe there is no pregiven world and the ontological nature of brought forth worlds as well as what this actually entails. The first and most important point to note is that the notion of bringing forth a world is ultimately an epistemic notion concerned with an organism's perspective on and knowledge of the world. This perspective, as we have seen, is grounded on the organism's distinct perceptual system and thus forms the basis for its own unique world. Thus, contrary to what enactivists claim, what this seems to entail is that organisms do not and cannot have direct knowledge of the world-in-itself, as an objective predefined reality, but only perceiver-dependent knowledge (cf. Zahidi 2014). The "worlds" which are purportedly brought forth refer to the organism's perceptual world and not the world or worlds. The world(s), whatever this turns out to be and at least as far as this particular argument is concerned, remains ontologically separate from the organism.

The second point which follows directly from the first is that while the claim that organisms bring forth worlds clearly presupposes an ontological plurality or multiplicity of reality, on closer inspection what the enactive account offers is epistemic plurality and multiplicity. We can thus call this position a form of epistemic perspectivalism (De Jesus 2016c). Organisms share one world but have multiple epistemic perspectives on it. Finally, this goes someway towards clarifying what the ontological status of the different worlds invoked by enactivism are: as the account is presented, there are no, there cannot be, multiple ontologically different worlds in sense-making - no organismic worlds - only multiple perspectives on the world of which organisms have only partial knowledge. It should now also be fairly clear that it is by unwittingly epistemologizing ontology that enactivism reaches its distinct conclusions. While to all intent and purposes concerned with the ontology of organismic worlds, these worlds are however rendered epistemic in the process.

In sum, this section has attempted to establish how exactly the world is brought forth rather than pregiven. In so doing we clarified that "worlds" are ultimately grounded on the organism's sensorimotor couplings with the world and thus perspectival in nature. It was also shown that ultimately it was by virtue of epistemologizing ontology that enactivism reached its conclusions. Thus, what is in the first instance introduced as multiple ontologies, turns out to be multiple perspectives. In my view enactivism is correct in emphasising that organisms bring forth worlds, worlds in the plural, but simply falls short in delivering a plausible ontological account of these worlds. Some might think this is a good thing, I will show in the next section however the very opposite.

\subsection{Epistemic multiplicity and the spectre of perspectivalism}

Before explaining why the notion of worlds in the plural is something that enactivism should be aiming to establish, we first need to (i) clarify what epistemic perspectivalism is and (ii) explain why it spells problems for the enactive account of agency.

According to the anthropologist Annemarie Mol (2002, 2004), from whom I take my understanding of the notion, perspectivalism is essentially an implicit metaphysical assumption that there is a singular pregiven world "out there" on which we can have different perspectives. From an epistemic perspectivalist standpoint, reality is singular and contains universal, intrinsic organism-independent properties, which can be 
multiply observed and possibly discovered but remain essentially unaffected by these observers. Perspectivalism thus understood involves two distinct but mutely reinforcing commitments: (i) a commitment, be it implicit or explicit, to the idea that there is a singular reality which (ii) can then be epistemically represented courtesy of the multiple perspectives taken on it.

To help focus this notion of perspectivalism the sociologist John Law (2009) points out that "[t]here are two great views of method in science and social science. On the one hand it is usual to say that methods are techniques for describing reality. Alternatively it is possible to say that they are practices that do not simply describe realities but also tend to enact these into being". Law argues that the first approach is part and parcel of the received wisdom informing most common-sense understandings of research methods and is grounded on the assumption that "in one way or another reality has a definite form that is substantially independent of and prior to the tools used to inquire into it" (ibid.). Scientific practice here revolves primarily around processes of discovering and describing - representing - this independent reality in the most accurate way possible.

The analysis provided in the previous two sections strongly suggest that, contrary to what is explicitly argued, the enactive account of agency appears to be unwittingly committed to the first aspect of perspectivalism. This is bound to strike many as not only absurd but at best as nothing more than a blatant misreading of the enactive account. After all, as we saw above, at the very core of the enactive account is the rejection of a pregiven world. So, if perspectivalism subsumes the view that takes the world to be pregiven and fixed, then surely enactivism cannot be accused of endorsing or perpetuating it. Initial appearances and protestations notwithstanding, we now have several reasons to seriously question this conviction.

We have already seen above, at various points throughout articulating and defending its distinctive account of agency, that enactivism has tended to epistemologize ontology. This inadvertent epistemologization of ontology can now be seen as the first true manifestation of a tacit commitment to epistemic perspectivalism. This is because, while explicitly making ontological claims, it clearly remains strictly within an epistemic register. This appears to be motivated by, at least prima facie, a post-Kantian conviction that we can never really know the world-in-itself but only have access to our own experiences which are themselves already formed by human categories (Ferraris 2014). The enactive conception of a brought forth world is clearly underpinned by something very close to this rough schematisation of organismic relatedness to the world. This however places both our understanding of organisms and organismic relatedness to the world on a primarily epistemic footing. But, if one wants to successfully argue that there is ontologically no pregiven world only multiple worlds, then one must aim to overcome this post-Kantian intuition. As our discussion above strongly suggests, in this particular context at least, enactivism simply fails to successfully shift the focus away from knowledge of the world to the materiality and composition of the world itself.

The crucial point then is that enactivism cannot adequately address ontological questions - what is this world that is brought forth? - through strictly epistemic means. And insofar as it does this it inevitably plunges head-deep into perspectivalist waters and cannot avoid the conclusion that the world remains pregiven after all. Thus, even though it strongly rejects the notion of a pregiven world it does not and arguably cannot 
overcome it. And the main reason for this is clear: by proposing a history of viable structural coupling as the "mechanism" responsible for the creation of unique ontologically multiple worlds it does so in the guise of a thoroughly epistemologized ontology. It conflates an organism's perspective on the world - knowledge/experience of the world - with the world itself. But this in no way guarantees, nor can it, that the world is not pregiven.

Recall the example of colour vision presented by Varela et al. as a prime example of a domain which is brought forth not "found pregiven". Clearly what we have in this example is a conflation between experiences of the world and the world itself brought about due to a epistemologizing of ontology. But even if different organisms do in fact experience the world differently it does not follow from this that there is no pregiven world. All this shows is that different organisms epistemically perceive and experience the world differently. Again the point to highlight here is that all this argument shows is that organisms have different perceptual experiences of one and the same world and not different worlds as such. Enactivism thus needs substantially more than the epistemic and abstract notion of structural couplings to effectively overcome the conviction that there is a pregiven world. And insofar as it remains strictly an epistemic project, enactivism will find it difficult to provide an adequate ontological answer to what there $i s$ if not a pregiven world.

Enactivism is evidently, and this follows naturally from the above, also committed to and openly embraces the second aspect of perspectivalism. As Vörös et al. (2016) point out, enaction "should not be taken as a description of what the mind is like, but more like a useful heuristic". Similarly, Thompson (2007, p. 50) suggests that "autonomy" and "heteronomy" are "heuristic notions" and "cognitive aids" which guide scientific enquiry. In other words, these are epistemic constructs - representations - which scientists can use to describe/articulate/model a target phenomena. ${ }^{6}$ Thus, while these might arguably be more fruitful than mainstream scientific/biological epistemic concepts and constructs for understanding and describing the target phenomena, they are epistemic constructs all the same.

Before pursuing this point any further let us pause here to take note of the contradiction which has emerged for the enactive account. In a nutshell, not only is enactivism unable to convincingly justify its own rejection of a fixed pregiven world, it consequently gets saddled with the very idea it is trying to reject. ${ }^{7}$ This is in turn confounded, reinforced and exemplified by the fact that it not only takes organisms themselves to have perspectives on the world but also uncritically regards its own concepts and ideas as merely epistemic representations of the world. Thus as things stand enactivism neither satisfactorily justifies its contention that there is no pregiven world nor explains how organisms brings forth worlds. Ultimately what the enactive account does is multiply perspectives - representations - rather than worlds.

This representationalism however makes it rather difficult, if not impossible, for enactivism to adequately account for the unique ontological liveliness, agency and material worlds of nonhuman organisms. Note however that, although

\footnotetext{
${ }^{6}$ This is also evident in the mechanistic and phenomenological arguments explored above. Enactivists do not regard their account of agency as being itself an enactment of agency but rather as an accurate, naturalistically sound, representation/description of agency.

${ }^{7}$ It is also worth noting here that, despite insisting that there is no pregiven world with intrinsic perceiverindependent properties, organisms seemingly fall outside the scope of this general thesis.
} 
connected to notions of mental representations more familiar to debates within enactivism, the representationalism involved here is somewhat distinct and less discussed in the literature. ${ }^{8}$ The representationalism involved here, as noted above, stems from the epistemic perspectivalist's commitment to the idea that the main aim of a naturalistic sound science is to observe and represent nature (Barad 2003, 2007; Pickering 2017). It is the primary job of the scientist to produce knowledge (descriptions, theories, concepts, models) which can get at and is said to mirror or correspond to, the true structure of reality. As we have seen, enactivism, although not explicitly aiming to uncover the ultimate structures of reality, sees its own account in such representationalist terms.

The problem with this type of representationalism is, in a nutshell, that it effectively renders material realities not only singular but also inaccessible. it impedes us and all living organisms ${ }^{9}$ from dealing with the material world directly and allows us access only to multiple representations of the world (Barad 2007). Agents and objects are in the process turned into mere shadows of themselves. As Bruno Latour points out, anyone committed to this type of representationalism inevitably "risk[s] falling back on the idea that there is, on one side, that which exists, and, on the other, "representations" of that which exists. In this view, existence would always be a unity; representations alone would be multiple" (Latour 2013, p. 234).

Even though organisms are regarded as lively sense-making entities with an intrinsic teleology, self-generated values, purposes etc, they are nevertheless only epistemically represented in this manner. As such, neither organisms nor the worlds they supposedly bring forth, despite appearance to the contrary, are accounted for ontologically in their own right but are instead reduced to abstract epistemic phenomena. The enactive account thus remains deeply caught up in its own knowledge, its manifold representations, of living organisms and their material worlds. While enactivism recognised and aimed to address the issue of mental representation, it completely overlooked this more ubiquitous form of representationalism and its implications. ${ }^{10}$

To sum up, we have argued in this section that enactivism is committed to epistemic perspectivalism and that this leads it into two distinct but connected difficulties. The first difficulty is that it generates some internal contradictions within the framework. While the second difficulty relates to its underlying epistemic/representationalist nature which makes it difficult to adequately account for the ontology of organismic worlds. If the above analysis is on the right track then enactivism not only fails to show that there is no pregiven world but also does not deliver the multiple worlds it promised.

But how else could we avoid these tensions and account for the ontological multiplicity or organismic worlds? In what remains of this paper I will aim to answer this question by sketching an account that both consistently rejects the notion of a pregiven world and coherently endorses, without falling into the trap of perspectivalism, the strong metaphysical thesis that organisms bring forth worlds.

\footnotetext{
${ }^{8}$ But see Heras-Escribano et al. (2015) for some discussion around similar issues.

${ }^{9}$ Because according to enactivism, just like all human beings, all living organisms have perspectives on the world.

${ }^{10}$ Although I cannot address this issue here further, I wold nonetheless like to highlight the structural similarities between this form of representationalism and mental representationalism.
} 


\section{From sense-making to bio-semiosis: Or how to overcome perspectivalism}

Enactivism correctly rejects the idea that there is a fixed pregiven world but ultimately fails to provide adequate arguments for this claim. But how else could we account for ontologically multiple worlds? In this final part of the paper we will sketch out the beginnings of a possible answer to this question by drawing on biosemiotic enactivism, science and technology studies (STS) and ontological anthropology. We will begin by first re-tweaking enactivism itself and then recast it in terms of a performative ontology.

\subsection{Biosemiotic enactivism}

Biosemiotic enactivism (BE) was introduced by Paulo De Jesus (2016b) as both a means to plug some of the purported blindspots of enactivism and to contribute to the development of enactive cognitive science itself. At its core is a proposed "synthesis" between biosemiotics ${ }^{11}$ in the Peircean tradition (Favareau 2007; Hoffmeyer 2008; Kull 1998) and autopoietic enactivism as presented above. BE endorses enactivism's strong life-mind continuity but grounds it on Uexküll's Umwelt theory and the bio-semiosis (sense-making/meaning-making) of living organisms (see also Meacham 2016). ${ }^{12}$

In so doing BE explicitly distances itself from enactivism's reliance on Hans Jonas and suggests in its place, following Morten Tønnessen (2011), a "Uexküllian phenomenology". Which, "is loyal not to Uexküll thought in detail but to the essential finding that nature is constituted by the intricate relations of all living creatures, which are all subjects of the phenomenal world at large" (Tønnessen 2011, p. 331). These relations are in turn conceived as bio-semiotic processes involving, at its most foundational-level, iconic (similarity-based) or/and indexical (causal) and at its most developed-level symbolic (conventional) signs. Signs here are not to be confused with concepts, mental representations or fixed pregiven "things" in the world, but as that which constitutes the relational basis of organismic engagement with their worlds (De Jesus 2016b, Hoffmeyer 2012). This allows De Jesus to propose that living organisms should be considered in terms of hierarchically structured processes of progressive complexification, from "basic" single cell organisms to "complex" multicellular animals such as humans, on the basis of the different signs these organisms are capable of using and creating. For BE cognition is co-extensive with bio-semiosis ${ }^{13}$ and thus a reflection of the organismic ability to both use and create signs in the heterogenous

\footnotetext{
${ }^{11}$ Biosemiotics, somewhat like enactivism, is still a field in its developing stages constituted by a loose group of connected yet different approaches. For an overview of the distinct "schools" and their relation see Barbieri (2009). For an exploration and comparison between enactive and biosemiotic approaches to agency see Tønnessen (2016).

${ }^{12}$ Recently Meacham (2016, p. 83) has taken issue with De Jesus's ambitions to “de-Kant” Uexküll's Umwelt theory by arguing that it "is not possible to fully de-Kant von Uexküll's Umwelt theory without losing precisely the essence of the concept of Umwelt, its specificity". The following sections could be read as an attempt to do just that.

${ }^{13}$ De Jesus (2016b) introduces the term "bio-semiosis" (with the hyphen) to designate sign-involving processes which are (i) co-extensive with cognition and (ii) organism level processes. This is contrasted with the term "biosemiosis" as used within biosemiotics to designate sign-involving processes that not only appear at an organism level but also below it. This leaves open the possibility that some sort of sign-involving processes (biosemiosis) could appear below the level of whole organisms though not cognition (bio-semiosis). This possibility strongly suggests that biosemiosis is a necessary precursor to bio-semiosis. I am grateful to a reviewer for insisting on clarification of these terminological distinctions.
} 
processes which contribute towards the maintenance of life. Cognition is here understood as "the active and creative process of bio-semiosis by bio-semiotic systems" (De Jesus 2016b, p. 139). ${ }^{14}$

An important consequence of placing this conception of signs at the core of life and mind is that signs become that which not only enable organisms to flexibly adapt their activities to constantly changing conditions but also serve as means of coordination and communication among and between diverse species. And, as Haraway (2008) notes, communication always, to some extent, involves communion with and a "becoming with", others. Indeed, according to Haraway (2003, p. 6) "Beings do not preexist their relatings". Therefore, to fully appreciate the diversity inherent within the biological world, we cannot begin with a single organism. This is an insight that BE takes seriously and enables it to take sociality as an ontologically constitutive dimension of life and mind. As sociality is crucial for the alternative proposal presented here, I will dedicate the rest of this section to further elaborating it.

For BE, a nonnegotiable but often overlooked implication of adopting a life-mind continuity thesis is that, sociality needs to be taken as a fundamental ontological condition of organismic life itself. That is, a commitment to life-mind continuity requires one to acknowledge that sociality is not only to be found in the human domain but inherent in life itself, beginning already with single cell organisms. There cannot be sociality without "individual" organisms but, unlike what the single cell example strongly suggests, without sociality there cannot be any individual organisms. This general, but important insight, is by no means new and can already be found in pragmatism and more recently in biosemiotics and certain strands of anthropology.

Inspired by research within biosemiotics (see Barbieri 2007; Favareau 2007) BE maintains that the common thread enabling most of sociality across the living world is the inherent ability for coordination and meaningful communication found both amongst and between species. Without an affective means of communicating amongst each other there would be no social groupings and therefore no sociality. In its most primordial manifestations, sociality is simply a dynamically unfolding field of entangled relations, enabled by a viable means of communication, connecting organisms in a multitude of complex ways to each other. All organismic life inhabit worlds of communication and signification and could not survive without this capacity. Because organisms live in communities and not in isolated hermetically sealed worlds, communication processes become that on the basis of which individual behaviour and the larger community are structured and organised. BE thus maintains that life processes, life itself, is of fundamental necessity inherently communicative and therefore social.

This undoubtedly makes good evolutionary sense on the grounds that, as Kawade (2009) argues "Sociality [...] had an important role to play also in the birth of life on the earth, because early forms of living things may well have been fragile and incomplete, and those which could interact with others to help each other would have been more successful". Therefore, from the coordinated behaviours of bacteria to the

\footnotetext{
${ }^{14}$ Note that as currently developed it remains unclear if BE is tacitly committed to perspectivalism. De Jesus (2016b, p. 142 italics added) claims that BE "allows us to accommodate and foolhardily embrace, the rich diversity ubiquitous in living nature and fully appreciates that all of these have unique perspectives on their world". Thus, if BE does not want to be saddled with the spectre of perspectivalism, it needs to clarify its ontological commitments. The following sections can be regarded as a contribution towards that end.
} 
languaging of humans, none would be possible without the ability for mutually reciprocal cooperative communication.

BE thus aims to bridge the gap which exists between human sociality and the sociality of nature by demonstrating that bio-semiosis - processes of meaning and signification - are inherent in, and exist between, all organismic lifeforms. Life is intrinsically social from the very beginning and relationship is thus primary to individuality. ${ }^{15}$ We now need to ground this $\mathrm{BE}$ account in a manner which will allow us to both overcome the idea of a pregiven world and enable us to make a coherent case for the notion that organisms bring forth ontological multiple worlds.

\subsection{From epistemic perspectivalism to ontological multiplicity}

In order to avoid falling into the trap of epistemologizing ontology as enactivism does we will need alternative resources to help us coherently account for the multiplicity of worlds. We need, first and foremost, a substantially different conception of ontology. An alternative approach to ontology, developed within science and technology studies (STS), anthropology and feminist science studies (Barad 2007; Kohn 2013; Haraway 2008; Latour 2013; Law 2004; Mol 2002), provides us with just what we need. These approaches aim to critically move ontology beyond the epistemic descriptive/ conceptual level and onto the realm of concrete materiality, contingent assemblages and performative enaction. It rejects both overly abstract notions of ontology which reduce it to "schemes of clarification and representation" (Pickering 2017), as the enactive account tacitly does, and also more traditional metaphysical synchronic notions which take ontology to be a study into the ahistorical and transcendent universal structure of "Being" and reality in general. ${ }^{16}$

Inspired by insights derived from this work, the central thesis to be defended here is that realities, note not reality in the singular, is the contingent consequence of the performative enactments undertaken by all living organisms. This renders being itself diachronic, deeply contingent, temporal and always-already in the making. Note moreover that, as it will be used in the rest of the paper, the term "ontology" draws a deliberate contrast not only with representationalist/ perspectivalist epistemology but also mono-realism. ${ }^{17}$ I will begin by unpacking and clarifying these ideas and then turn to connect them with the BE account outlined above.

\footnotetext{
${ }^{15}$ This proposal is in contrast to the anthropocentric account of sociality found in enactivism which is almost exclusively concerned with human sociality. See Cummins and De Jesus (2016) for a critique. For BE the template for sociality is drawn from the entangled interconnect nature of organismic life itself rather than the human domain.

${ }^{16}$ This work has its roots in STS and actor network theory (Latour 2013) and has more recently found a host of proponents within anthropology, philosophy and feminist theory. Within anthropology and STS this work has come to be known under the umbrella term "the ontological turn" (see for example Descola 2013; Kohn 2013; Holbraad and Pedersen 2017; Pickering 2017; Viveiros de Castro 2014). See Gad et al. (2015) for an excellent overview of some of these developments.

${ }^{17}$ Note that this is a rejection of mono-realism, the view that there is only one fixed reality, not realism as such. Reality exists but its just much more malleable, fluid and plural then we have tended to imagine. The position presented here is therefore not a defence of a purported "middle ground" between realism and idealism as enactivism strives for.
} 
What we might call, echoing Pickering (2017), a performative ontology, requires first and foremost a shift of focus from our knowledge of the world to the materiality of the world(s) itself as it is contingently enacted through entanglements of material practices. To do so requires a deliberate and focused move away from the apparent inevitability of an epistemology of representing living organisms and their worlds from a human-centred perspective, towards acknowledging and accounting for the concrete ontologically multiple realities performed by all living organisms themselves. These multiple realities and their constitutive and ontological new entities are the enactments of organisms themselves in ever changing temporal contexts, material reconfigurations and concrete practices. Here human reason or knowledge can no longer be taken as the ultimate arbiter of reality. ${ }^{18}$

Drawing inspiration from the ethnographical work done by Annemarie Mol (2002), the performative ontology proposed here rejects the view that we are mere onlookers of a pregiven reality. As such, all living organisms are actors who not only impact on how reality is perceived and experienced (as in the enactive account explored above), but more importantly on the materiality of reality itself (Barad 2007). To flesh out and contrast it with the enactive view, consider how according to Mol (ibid), the objects and phenomena we take as settled, scientifically quantifiable and observable are not really just objects-inthe-world; but rather, always ontologically multiple. Reality, as enactivists correctly maintain, is not a pregiven out there which we passively observe and is only fully revealed to us by scientists or astute metaphysicians. But whereas enactivism epistemologizes ontology and as a consequence fails to truly appreciate let alone address the question of what there is if not a pregiven reality, work done by Mol and colleagues, confronts this very question head-on. Reality, what there is, is worlds in the plural, and these worlds are the ontological consequence of historical, diachronic, context-dependent, concrete but relational, materially contingent practical enactments. ${ }^{19}$ As John Law (2015, p. 127) argues, the real is simply the "effects of contingent and heterogeneous enactments, performances or sets of relations".

While perhaps thought provoking, the central point is straightforward: rather than simply take for granted that there are only many ways of knowing or representing "an object", it is argued that there are instead many ways of practising/doing/enacting an object. Thus new forms of objects and indeed agents are formed and reformed shape and are reshaped by and within the diachronically contingent assemblages of other objects, agents, technologies and other heterogeneous materials with which these continuously engage. That is to say, concrete material practices with their ever shifting material reconfigurations, lead to new organism-specific makeshift ontological entities

\footnotetext{
${ }^{18}$ The point here is that the multitude of organismic worlds which exist apart from us cannot be held hostage by the question of our human (epistemic) access to them. If we want to do justice to these we need to overcome the overwhelming anthropocentric tendency to take "Man" as the measure of all things.

${ }^{19}$ It must be noted from the outset that the notion of enactment used here is similar yet importantly distinct from that used within enactivism. The crucial difference is that, as used here and in the following sections, the notion is conceived ontologically: as that on the basis of which new ontological entities are practically constituted and materialised. The enactive conception is not ontological but a species of epistemologized ontology.
} 
and phenomena. The key to this ontological multiplicity is concrete material practices. ${ }^{20}$ As Mol argues, once "practices are foregrounded there is no longer a single passive object in the middle, waiting to be seen from the point of view of seemingly endless series of perspectives. Instead, objects come into being - and disappear - with the practices in which they are manipulated. And since the object of manipulation tends to differ from one practice to another, reality multiplies" (Mol 2002, p. 4).

The general idea is eloquently illustrated by Mol's (ibid) ethnography of atherosclerosis. She demonstrates how this medical condition is, through various practices and material reconfigurations, ontologically enacted in multiple ways. For example through a patient's suffering from a painful discoloured leg presented in an outpatient clinic, through arteriosclerotic plaque which blocks blood vessels and are operated upon in an operating theatre or in a laboratory where the blood of a sufferer is examined. In each case, argues Mol, atherosclerosis is enacted differently in historically sensitive, sociocultural and context-specific concrete material practices, such that an ontologically new "entity" is brought into being in each instance. Thus, rather than seeing these different manifestations of atherosclerosis as mere epistemic perspectives taken on a single, universal stable condition, it is regarded to be ontologically multiply constituted. Generalising this example we are led to a position where worlds, novel ontological entities and phenomena, are continuously being concretely made - enacted - through historically situated, temporally co-evolving webs of entangled relations constituted by a multitude of agents, assorted materials and technologies.

Moreover, by emphasising the ontological entanglements of human and non-human actors in these contingent material practices, we are at the same time also mounting a strong challenge against and reconfiguring traditional epistemology and epistemic/ representationalist grounded accounts of science. This is because the more traditional epistemic activities, such as observing and representing, are no longer seen as distinct from what Ian Hacking (1983) calls intervening or constructing but are rather understood as specific ways of intervening on and constructing worlds. As Karen Barad (2007) argues, practices of knowing, such as observing and representing, are just specific material engagements whereby worlds are continuously reconfigured and made and not disengaged representing. In this respect epistemology simply collapses into ontology and we in effect have a reversal of enactivism's epistemologized ontology. Thus, as the above quote from John Law maintains, all scientific practices enact unique realities rather than merely describe them. Representationalist based sciences are here reconfigured as entangled practical activities which continuously manifest new

\footnotetext{
${ }^{20}$ It is important that we recognise here a crucial difference between my appeal to practice and the enactive theory's appeal to practice. As is well known enactivism places practice and the concrete engagement of organisms with the world at the very core of its framework. However, the appeal to practice by enactivism, is used precisely as a means of generating knowledge of and thus represent (conceptualise/model/theorise) how organisms interact with their environment. By contrast, my appeal to practices here is used as a means to render explicit how organisms create diverse worlds through these heterogeneous material entanglements. Enactivism mobilises practices epistemically while I am suggesting an ontological conception which is concerned with the world(s) rather than our knowledge of it. Thus practices do not merely describe but ontologically materialise objects and phenomena. Furthermore, this notion of practice is inspired by Isabelle Stengers's (2005) contention that "no practice can be defined as any other, just as no living species is like any other. Approaching a practice then means approaching it as it diverges, that is, feeling its borders, experimenting with the questions which practitioners may accept as relevant, even if they are not their own questions" (2005, p.184). I am grateful to a reviewer for pressing me for further clarification on this issue.
} 
ontological elements with new capabilities and which enable new webs of relations and close off others.

To brings these various threads together, the performative ontology sketched above opens up possibilities for difference and multiplicity rather than provide singular universal truths about the essence of reality itself. We have argued that reality - no longer the world but worlds in the plural - is neither fixed nor pregiven but rather temporal and diachronic, malleable, fluid and ultimately multiple. This malleability and multiplicity was shown to be creatively realised in a multiplicity of ways under different interactions and within different contexts, all of which lead to new, often unpredictable, makeshift organism-specific ontological entities. Finally, as Law (2004) correctly observes, this turn to ontological multiplicity allowed us to shift focus from representations as entities which aim to mirror the true nature of a singular reality to the material objects themselves as they are multiply enacted, and thus avoid some of the pitfalls of representationalism.

And thus we have provided the beginnings of an answer to both enactive questions; what is there if there is no pregiven world and how can organisms bring forth worlds which are not grounded on perspectives. Our proposal was principally premised on a move from epistemology - from what we know - to a practical and deflationary conception of ontology - to what there is and how it is done. This enabled us to both address some of the potential excesses of an uncritical representationalism and the pitfalls of inadvertently epistemologizing ontology. With this we now have all the pieces to assemble our BE account of organismic world constitution.

\subsection{Bio-semiosis: Worlds without perspectives}

What a performative ontology gives us is multiple worlds as ontologically constituted through concrete material enactive engagements. What I now want to do is take the above insights and use them as the basis to argue that all living organisms enact ontologically multiple worlds which are immensely richer and more diverse than the epistemic representational artefacts inferred from a human-centred perspective. In other words, there are other (multiple) realities beyond the human. In order to do so we need to bring BE back to the table.

If we ground $\mathrm{BE}$ on a performative ontology, the practices and relations - enactments - on the basis of which multiple realities emerge, can be conceived as (i) meaningful processes of bio-semiosis involving signs which (ii) are performed by all living organisms and not humans alone. Because bio-semiosis is a process of signification and because nonhuman living organisms can also use signs they too need to be regarded as meaning-making creatures. This enables us to make genuine ontological claims about both meaning and reality beyond the human domain. But unlike enactivism we are not doing so by epistemologizing ontology, by drawing on our own lived experience or abstract models and representations. Rather we are doing so by ontologically grounding, in the sense sketched out above, all processes of bio-semiosis. All living organisms, human and nonhumans alike, are spontaneously responsive and creative enactive embodied beings. All lives inhabit an entangled web of intermingled enacted material realities guided by natural and artificial signs. Within these dynamic unfolding realities of agential bio-semiotic activity, nothing exists in complete separation from anything else. Through these webs of 
relations all organisms ontologically enact their own unique worlds with their own ontological distinct entities.

To illustrate this ontological reformulation of BE, consider for example, the spider which casts its web in a particular location in order to catch flies or the bird which feigns a broken wing so as to lure away a predator from its nest. In both these examples the organism benefits from its creative ability, which is either acquired through phylogeny or ontogeny, to multiply enact certain covariant regularities - signs - in its environment. Insofar as these covarying relations are enacted by the organism they are bio-semiotic relations. The spider uses the relations between sun and shadows as a guide to cast its web. While the bird has developed the ability to not only recognise the connection between clumsy movements and an easy pry which informs certain predators, but also that these movements can fool predation. Note moreover that, due to their bio-semiotic nature, in either case these relations can fail to yield the intended outcome: flies aren't always caught in the web and predators aren't always fooled by the bird's pretence. This is due to the fact that bio-semiotic relations are not efficient causal (dyadic) relations but involve what Hoffmeyer (2012, p. 375) calls triadic "semiotic causation".

For BE, neither the spider nor the bird, are regarded as having perspectives on their world. Rather, they have a reality which is ontologically enacted through concrete, contingent, diachronic, material processes of bio-semiosis. Realities are done and ontologically distinct entities are enacted into being in contingently shifting assemblages of heterogeneous practices, which include both other objects and agents, of open-ended becoming. Note that here we retain the enactive intuition that these relations are meaningful for the organism but deny that they are perspectives the organism takes on the world. These just are the ontologically enacted realities of the organism. Importantly, these realities are not solipsistic "soup-bubbles" as Uexküll suggests. Rather, by (i) shifting from epistemology to ontology and (ii) placing sociality at the core of its account, BE understands these as always other-involving and ontological worldly enactments.

This should go someway towards further clarifying how it is that organisms in general and not just human beings alone can have unique worlds rather than mere perspectives or "points of view" on the world. To try and avoid possible confusion it will be worth pausing here to further unpack this claim. The first point to note is that, if worlds are in fact brought forth as enactivists maintain, then surely no organism can have a point of view or perspective on it. Enacting something, in the stricter ontological sense developed here, precludes the possibility of taking a perspective on it. ${ }^{21}$ The move to a performative ontology should make this point fairly clear.

Putting this aside for the moment, some readers might want to object that, on the surface at least, the alternative BE proposal defended here appears to be committed to precisely such a claim vis-à-vis the bio-semiosis of the living. Not so. As we saw above the enactive "point of view" is an epistemic one: different systems have a point of view

\footnotetext{
${ }^{21}$ A reviewer of the paper objected to this claim by pointing out that it is not phenomenologically inconsistent to maintain that an organism both enacts objects within a perceptual field and also has a perspective upon them. This being the case, objects can then be said to be enacted with a certain perspective such as for example a spatial perspective. I agree that this is indeed the case if one take enaction to be an epistemic notion. However, if enaction is conceived ontologically this is no longer the case, because taking a perspective (e.g. a spatial perspective) on an object just is another type of (ontological) enactment.
} 
on the world, a perceptual schematisation of objects. Although BE is sympathetic to some of the intuitions motivating aspects of this claim it nonetheless reverses it by, as we have seen above, ontologizing it. To reiterate, rather than claiming that all living organisms have unique points of view, BE maintains that all living organisms enact ontologically unique realities. It is in this sense that realities are argued to be done rather than just observed. If so, then a living organism's existence is more than a 'point of view' onto reality, it is a reality in itself(Viveiros de Castro 2004). A kinship analogy drawn from the anthropologist Viveiros de Castro might help further bring home this point.

As Viveiros de Castro points out, "Isabel is not a mother "for" Michael, from Michael's "point of view"...she's really and objectively Michael's mother, and I am really Michael's uncle" (2004, p. 110). The same, holds BE, applies to all organismic worlds. Just as the properties of being a son, a mother or an uncle, are real objective properties which exits by virtue of the enactment of a very specific set of relations, so too are the objects, entities and varied phenomena ontologically uniquely enacted by all living organisms through processes of bio-semiosis. The multiple objects, entities and varied phenomena enacted by different organisms are ontologically real and not mere points of view or perspectives on the real, neither for the observer nor the observed.

Finally, note that this ontological approach also helps us to re-inscribe difference into the very fabric of the living world. There is an inherent diversity to organismic agencies and worlds which cannot be reduced to the disparity of endless perspectives. Enactive sense-making, in being excessively focused on both the epistemic and phenomenological, has obscured ontological difference pertaining to the living world and tends to slide into an unwarranted anthropocentrism (De Jesus 2016a). The approach sketched out above takes some steps towards rectifying this by opening up a space for the ontological manifestation of the rich diversity of all living organisms which can dignify the multiplicity of their idiosyncratic meaningful worlds. It goes beyond the anthropocentric bias of enactivism by providing a means to recognise and appreciate the manifold diversity inherent in nature. But, note again that difference has been cast as ontological rather than epistemological, so as to ensure the richer ontology of worlds and not lapse into world-views or perspectives. As Donna Haraway points out, "we learn to be worldly from grappling with, rather than generalizing from, the ordinary" (Haraway 2008, p. 4).

To sum up, we have sketched out an account which has aimed to do justice to the ontological multiplicity of brought forth worlds. In the process we opened the door to the existence of ontological properties unique to and which form the constitutive building blocks of different organismic worlds. To do so we have had to eschew enactivism's proclivity to epistemologize ontology by first shifting focus from our knowledge of objects to the enactment of objects themselves and thus foregrounding the diachronic and contingent material practices within which new ontological, organismic-specific properties, were allowed to emerge. This enabled us to side-step attempts to characterise what it must be like for the organism to live in its own world from our perspective, and instead propose that we shift focus towards the new ontological properties which emerge within distinct organismic worlds through dense webs of relations and concrete material practices and routines. It was argued that all living organisms have meaningful worlds by virtue of their bio-semiotic abilities and capacities. Finally it was also argued that through processes of bio-semiosis organisms 
do not take perspectives on the world, but rather are in and thus have ontological worlds unique to their bio-semiotic capacities, material practices and relations.

\section{Agential entanglements and ontological reflexivity}

I want to conclude this paper by briefly considering the notion of reflexivity in light of the broader themes explored above.

We saw above that a central motivation for Cummins's embracing of "perspectivalism" was a desire to take the observer seriously. Cummins is particularly sensitive to the inherent reflexivity involved in all forms of scientific and nonscientific investigation. Given that we have rejected perspectivalism one might now want to ask how it is that we account for the role of the observer. Although it is beyond the scope of this paper to present a full account of reflexivity, I do nonetheless find it necessary to provide a few words on it.

As Vörös et al. (2016) point out, enactivism insists that one "acknowledges the ineradicable reflexivity of all our epistemic practices". Once we do acknowledge this we soon realise that there is no neutral position, no "view from nowhere", which an observer can take on reality. Not unlike the account of agency explored above this notion of reflexivity is firmly rooted in epistemic/representationalist grounds. This is particularly evident in the enactive treatment of the single cell bacterium where neither the bacterium nor the biologist ontologically effect each other in any significant way. The bacterium simply gets reduced to a set of abstract representations grounded on multiple perspectives (e.g. Thompson 2007, p. 154). But, with the collapse of epistemology into ontology, "ineradicable reflexively" becomes inevitably ontologically reconfigured. Consider the case of the bacterium again.

First point to note is that whether a biologist regards a bacterium as an agent or not will have no bearing whatsoever on the bacterium itself. However, once a researcher actively intervenes, by say, isolating a bacterium and variously experimenting on it, the ontological status of both the bacterium and the researcher, together with their respective agencies, do change. The bacterium is constitutively transformed and made into a distinctive object of study. While the biologist stops being a detached, passive and neutral observer merely representing the bacterium and becomes constitutively ontologically - implicated in the bacterium's manifested agency and world-constitution. There is thus an ontological agential entanglement here whereby the biologist, together with all the various lab technologies, tools and structures, coalesce to enact a distinctive bacterium. At the same time the bacterium also affects its agency on the biologist such that she too is ontologically constituted, made and remade, in order to attune herself to the bacterium so as to, among other things, render this newly contingent emergent world more visible. The point to highlight here is that reflexivity is not simply about epistemic access but rather about ontological constitution: about material entanglements and ongoing transformative processes of open-ended becomings (see Barad 2007).

The work of Natasha Myers (2015) provides a concrete account of this sort of agential entanglements found between biologists and the phenomena they study. Studying the work of protein crystallographers, Myers highlights not only the importance of embodiment in the modelling process but also how modellers inevitably 
become deeply entangled with and affected by the phenomena they study such that they must learn to feel their way through their collected data in order to render life physically molecular. According to Myers, protein crystallographers not only model biological phenomena, but are in this very process also themselves modelled by - ontologically constituted - the very phenomena. The point here is that biologists are not mere passive epistemic observers trying to uncover the "true" form and structure of proteins but rather active participants in their ontological becoming. Participants which are also, and indeed need to be, equally changed by the phenomena they are investigating so as to ontologically render it visible.

Once reflexivity is cast ontologically bacteria no longer possess an intrinsic nature which can only be variously represented by virtue of the multiple perspectives taken on them. Rather, bacteria are ontologically constituted within various material practices of inquiry: bacteria do not preexist these material relations but emerge within them. Different modes of enactment vary depending where they are physically located, in the wild, in the lab etc, who is participating, for what purpose and so on. But it is important to recognise that in recasting reflexive agency ontologically we have at the same time also opened up a space for the bacterium to simply be itself. Bacteria are themselves agents which ontologically constitute and thus enact different unique worlds. In order to do justice to this point we must shift the focus from taking perspectives on the bacterium, to recognising the contingent material practical nexus within which it enacts its distinctive modes of being.

To bring these various threads together, we can sum up by saying that an ontologically grounded notion of reflexivity takes agencies to be both contingently and materially done. By taking this on board we have subverted the role of the human observer in the epistemic attribution of agency but recognised her potential ontological entanglement within organismic worlds. The importance of this is not so much that when enactivists use the example of a bacterium they are relying on a abstraction which purifies the delicate web of relations within which all bacteria make a living and are made a living of while enacting their respective agencies, which they certainly do, but rather that they also fail to (i) recognise how agency is itself done and (ii) how the observer herself can and must become ontologically rather than merely epistemically implicated in the enactment of multiple agencies.

Acknowledgements I would like to thank the two anonymous reviewers for very helpful comments and suggestions on earlier drafts of this paper. Many thanks to Tom Froese for reading and commenting on an earlier draft. Finally, I am extremely grateful and indebted to Fred Cummins, Simon McGregor and especially Mark Bishop for extensive discussion on all the issues presented here and for reading countless earlier drafts.

Open Access This article is distributed under the terms of the Creative Commons Attribution 4.0 International License (http://creativecommons.org/licenses/by/4.0/), which permits unrestricted use, distribution, and reproduction in any medium, provided you give appropriate credit to the original author(s) and the source, provide a link to the Creative Commons license, and indicate if changes were made.

\section{References}

Barad, K. (2003). Posthumanist performativity: Toward an understanding of how matter comes to matter. Signs: Journal of Women in Culture and Society, 28(3), 801-831. 
Barad, K. (2007). Meeting the universe halfway: Quantum physics and the entanglement of matter and meaning. Durham: Duke University Press.

Barandiaran, X., Di Paolo, E. A., \& Rohde, M. (2009). Defining agency: Individuality, normativity, asymmetry, and spatio-temporality in action. Adaptive Behavior, 17(5), 367-386.

Barbieri, M. (Ed.) (2007). Introduction to biosemiotics: The new biological synthesis. Dordrecht: Springer.

Barbieri, M. (2009). Three types of semiosis. Biosemiotics, 2(1), 19-30.

Barrett, N.. (2015). The normative turn in enactive theory: An examination of its roots and implications. Topoi (online first). https://doi.org/10.1007/s11245-015-9355-y

Chemero, A. (1998). A stroll through the worlds of animats and persons: a review of Andy Clark's being there. Psyche, 4(14). http://psyche.cs.monash.edu.au/v4/psyche-4-14-chemero.html

Colombetti, G. (2014). The feeling body: Affective science meets the enactive mind. Cambridge: MIT Press.

Cummins, F. (2014). Agency is distinct from autonomy. AVANT. Pismo Awangardy Filozoficzno-Naukowej, 5(2), 98-112.

Cummins, F., \& De Jesus, P. (2016). The loneliness of the enactive cell: Towards a bio-enactive framework. Adaptive Behavior, 24(3), 149-159.

Davidson, D. (1963). Actions, reasons, and causes. The Journal of Philosophy, 60(23), 685-700.

De Jaegher, H., \& Froese, T. (2009). On the role of social interaction in individual agency. Adaptive Behavior, $17(5), 444-460$.

De Jesus, P. (2016a). Autopoietic enactivism, phenomenology and the deep continuity between life and mind. Phenomenology and the Cognitive Sciences, 15(2), 265-289.

De Jesus, P. (2016b). From enactive phenomenology to biosemiotic enactivism. Adaptive Behavior, 24(2), 130-146.

De Jesus, P. (2016c). Making sense of (autopoietic) enactive embodiment: A gentle appraisal. Phainomena XXV/98-99.

Descola, P. (2013). Beyond Nature and Culture. Janet Lloyd trans. Chicago: University of Chicago Press.

Di Paolo, E. A. (2005). Autopoiesis, adaptivity, teleology, agency. Phenomenology and the Cognitive Sciences, 4(4), 429-452.

Di Paolo, E. A. (2009). Extended life. Topoi, 28(1), 9-21.

Di Paolo, E. A., \& Thompson, E. (2014). The enactive approach. In L. Shapiro (Ed.), The Routledge handbook of embodied cognition (pp. 68-78). New York: Routledge.

Di Paolo, E. A., Rohde, M., \& De Jaegher, H. (2010). Horizons for the enactive mind: Values, social interaction, and play. In J. Stewart, O. Gapenne, \& E. A. Di Paolo (Eds.), Enaction: towards a new paradigm for cognitive science (pp. 33-87). Cambridge: MIT Press.

Egbert, M. D., Barandiaran, X. E., \& Di Paolo, E. A. (2010) "A minimal model of metabolism-based chemotaxis.” PLoS Computational Biology, 6(12), e1001004.

Favareau, D. (2007). The evolutionary history of biosemiotics. In M. Barbieri (Ed.), Introduction to biosemiotics. The new biological synthesis (pp. 1-67). Dordrecht: Springer.

Ferraris, M. (2014). Introduction to new realism (trans: De Sanctis, S.). New York: Bloomsbury Academic.

Fodor, J. A. (1975). The language of thought (Vol. 5). Harvard University Press.

Froese, T., \& Ziemke, T. (2009). Enactive artificial intelligence: investigating the systemic organization of life and mind. Artificial Intelligence, 173(3-4), 466-500.

Gad, C., Jensen, C. B., \& Winthereik, B. R. (2015). Practical ontology: Worlds in STS and anthropology. NatureCultures, 3, 67-86.

Hacking, I. (1983). Representing and intervening: Introductory topics in the philosophy of natural science. Cambridge: Cambridge University Press.

Haraway, D. J. (2003). The companion species manifesto: Dogs, people, and significant otherness (Vol. 1). Chicago: Prickly Paradigm Press.

Haraway, D. J. (2008). When species meet. Minneapolis: University of Minnesota Press.

Heras-Escribano, M., Noble, J., \& De Pinedo, M. (2015). Enactivism, action and normativity: A Wittgensteinian analysis. Adaptive Behavior, 23(1), 20-33.

Hoffmeyer, J. (2008). Biosemiotics: An examination into the signs of life and the life of signs. Scranton: University of Scranton Press.

Hoffmeyer, J. (2012). The natural history of intentionality. A biosemiotic approach. In: Schilhab, Theresa; Stjernfelt Frederik; deacon, Terrence (eds.), The Symbolic Species Evolved. (Biosemiotics 6) Dordrecht: Springer, 97-116.

Holbraad, M., \& Pedersen, M. A. (2017). The ontological turn: An anthropological exposition. Cambridge: Cambridge University Press.

Hutto, D., \& Myin, E. (2013). Radicalizing enactivism: Basic minds without content. Cambridge: MIT Press. Jonas, H. (1966). The phenomenon of life: Towards a philosophical biology. Evansto: Northwestern University Press. Kawade, Y. (2009). On the nature of the subjectivity of living things. Biosemiotics, 2(2), 205-220. 
Kohn, E. (2013). How forests think. Toward an anthropology beyond the human. Berkeley: University of California Press.

Kull, K. (1998). On semiosis, umwelt, and semiosphere. Semiotica, 120(3/4), 299-310.

Kyselo, M., \& Di Paolo, E. (2015). Locked-in syndrome: A challenge for embodied cognitive science. Phenomenology and the Cognitive Sciences, 14(3), 517-542.

Latour, B. (2013). An inquiry into modes of existence. Cambridge: Harvard University Press.

Law, J. (2004). After method: mess in social science research. London and New York: Routledge.

Law, J. (2009). Seeing like a survey. Cultural Sociology, 3(2), 239-256.

Law, J. (2015). What's wrong with a one-world world? Distinktion: Scandinavian Journal of Social Theory, 16(1), 126-139.

Maturana, H. R. (1975). The organization of the living: A theory of the living organization. International Journal of Man-Machine Studies, 7(3), 313-332.

Maturana, H. R., \& Varela, F. J. (1980). Autopoiesis and cognition: The realization of the living. Dordrecht, Holland: Kluwer Academic Publishers.

Mayr, E. (1992). The idea of teleology. Journal of the History of Ideas, 53(1), 117-135.

McGann, M. (2015). Situierte Handlungsfähigkeit: normatives Medium des menschlichen Handelns. Synthesis Philosophica, 29(2), 217-233.

Meacham, D. (2016). How low can you go? BioEnactivism, cognitive biology and umwelt ontology. Humana Mente - Journal of Philosophical Studies, 31, 73-95.

Mol, A. (2002). The body multiple: Ontology in medical practice. Durham: Duke University Press.

Mol, A. (2004). Ontological politics: A word and some questions. In J. Law \& J. Hassard (Eds.), Actor network theory and after (pp. 74-89). Oxford: Blackwell.

Myers, N. (2015). Rendering life molecular: Models, modelers, and excitable matter. Chicago: Duke University Press.

Pickering, A. (2017). The ontological turn: Taking different worlds seriously. Social Analysis, 62(2), 134-150.

Proulx, J. (2008). Some differences between Maturana and Varela's theory of cognition and constructivism. Complicity: An International Journal of Complexity and Education, 5, 11-26.

Pylyshyn, Z. W. (1988). Computing in cognitive science. London: University of Western Ontario, Centre for Cognitive Science.

Searle, J. R. (1980). Minds, brains, and programs. Behavioral and Brain Sciences, 3(03), 417-424.

Stapleton, M., Froese, T. (2015). Is collective agency a coherent idea? Considerations from the enactive theory of agency. In: Collective agency and cooperation in natural and artificial systems (pp. 219-236). Springer International Publishing.

Stengers, I. (2005). Introductory notes on an ecology of practices. Cultural Studies Review, 11(1), 184-196.

Stewart, J., Gapenne O., \& Di Paolo E. A. (Eds.) (2010). Enaction: Toward a new paradigm for cognitive science. Cambridge: MIT Press.

Thompson, E. (2004). Life and mind: from autopoiesis to neurophenomenology. A tribute to Francisco Varela. Phenomenology and the Cognitive Sciences, 3, 381-398.

Thompson, E. (2007). Mind in life: Biology, phenomenology, and the sciences of mind. Cambridge: Harvard University Press.

Tønnessen, M. (2011). Semiotics of being and Uexküllian phenomenology. In: Phenomenology/Ontopoiesis retrieving geo-cosmic horizons of antiquity (pp. 327-340). Springer Netherlands.

Tønnessen, M. (2016). Agency in biosemiotics and enactivism. In: Meaning, mind and communication: Explorations in cognitive semiotics. Peter Lang Publishing Group. pp. 69-82.

Varela, F., Thompson, E., \& Rosch, E. (1991). The embodied mind: Cognitive science and human experience. Cambridge: MIT Press.

Villalobos, M., \& Ward, D. (2015). Living systems: Autonomy, autopoiesis and enaction. Philosophy and Technology, 28(2), 225-239.

Viveiros de Castro, E. (2004). Perspectival anthropology and the method of controlled equivocation. Tipitii: Journal of the Society for the Anthropology of Lowland South America, 2(1), 2-20.

Viveiros de Castro, E. (2014). Cannibal metaphysics. Translated by Peter Skafish. Minneapolis: Univocal Press.

Vörös, S., Froese, T., \& Riegler, A. (2016). Epistemological odyssey: introduction to special issue on the diversity of enactivism and neurophenomenology. Constructivist Foundations, 11(2), 189-203.

Weber, A., \& Varela, F. J. (2002). Life after Kant: Natural purposes and the autopoietic foundations of biological individuality. Phenomenology and the Cognitive Sciences, 1(2), 97-125.

Werner, K. (2017). Coordination produces cognitive niches, not just experiences a semi-formal constructivist ontology based on von Foerster. Constructivist Foundations, 12(3), 292-299.

Zahidi, K. (2014). Non-representationalist cognitive science and realism. Phenomenology and the Cognitive Sciences, 13(3), 461-475. 